\title{
Gene expression profiling in myelodysplastic syndrome after SPARC overexpression associated with Ara-C
}

\author{
QING NIAN $^{1}$, ZHIQIANG ZHANG ${ }^{1}$, CHUNMEI WEI $^{2}$, XINGYI KUANG $^{2}$, XINGYONG WANG $^{1}$ and LI WANG $^{2}$ \\ ${ }^{1}$ Department of Emergency, Children's Hospital of Chongqing Medical University; ${ }^{2}$ Department of Hematology, \\ The First Affiliated Hospital of Chongqing Medical University, Yuzhong, Chongqing 400016, P.R. China
}

Received May 11, 2015; Accepted June 30, 2015

DOI: 10.3892/or.2015.4139

\begin{abstract}
Secreted protein acidic and rich in cysteine (SPARC) is involved in many biological processes, including erythropoiesis and cell proliferation. However, the role of SPARC in myelodysplastic syndrome (MDS) remains to be elucidated. Pyrimidine analogue cytosine arabinoside (Ara-C) is among the most effective agents used in the treatment of acute leukemia. The aim of the present study was to determine whether the chemotherapeutic activity of Ara-C was enhanced by the overexpression of SPARC. DNA microarray technology and RNA sequencing were employed to examine differential gene expression in the apoptosis signaling pathway after gene change occurred in cells following drug treatment. The results showed that upregulation of the expression of SPARC induced SKM-1 cell death and inhibited proliferation. Additionally, the apoptotic rate of SPARC overexpression combined with Ara-C increased significantly. Transcription factors CPBP and ZNF333 regulated the 69 genes and long non-coding RNA (lncRNA). Moreover, the mRNA and protein expression of apoptosis-related genes in the DNA microarray results were increased. These results suggest that SPARC expression changes with Ara-C, revealing a possible application in the treatment of MDS.
\end{abstract}

\section{Introduction}

Myelodysplastic syndrome (MDS) is a diverse group of neoplastic bone marrow disorders characterized by abnormal cell morphology and blood defects in the normal

Correspondence to: Dr Xingyong Wang, Department of Emergency, Children's Hospital of Chongqing Medical University, 136 Zhongshan Road, Yuzhong, Chongqing 400016, P.R. China

E-mail:wxy991818@sina.com

Dr Li Wang, Department of Hematology, The First Affiliated Hospital of Chongqing Medical University, 1 Youyi Road, Yuzhong, Chongqing 400016, P.R. China

E-mail: erin_wang77@hotmail.com

Key words: SPARC gene, myelodysplastic syndrome, transcription factor, IncRNA differentiation and proliferation of hematopoietic precursors. Various subtypes of MDS lead to acute myeloid leukemia (AML) (1). Chromosome aberrations in MDS have been previously elucidated, and it is now known that an interstitial deletion of chromosome 5 is the most common cytogenetic abnormality in MDS (2). In addition, the common deletion region (CDR) exists in 5q31-32 (3). One of the genes in this area is the osteonectin $(S P A R C)$ gene. Investigation into the relationship between the $C D R$ gene and cell biology facilitates further understanding of the pathogenesis MDS/AML.

SPARC has been described as a counter-adhesive, matricellular protein with a variety of biological functions associated with morphogenesis, remodeling, cell migration and proliferation (4). The expression of SPARC occurs in different types of cancer, however, its role in tumorigenesis appears to be complex and not well-defined (5). For example, SPARC expression is high in breast and colorectal cancer $(6,7)$, but low in prostate and lung cancer $(8,9)$. Moreover, haploinsufficiency of SPARC in the $5 q$-syndrome potentially increases the adhesion of hematopoietic stem cells to the supporting stromal cells, providing a clonal advantage (10). Elevated SPARC expression inhibits the growth of tumor cells in the 5q-syndrome, whereas a low expression leads to tumor development. Therefore lenalidomide, a drug known to elevate SPARC expression, has been used to treat patients with the 5q-syndrome (11).

Cytarabine (cytosine arabinoside, Ara-C) is commonly used as a treatment for MDS, when combined with other chemotherapeutic agents. It comprises pyrimidine antimetabolite, which interferes with the DNA synthesis of the cells in the $S$ phase of the cell cycle by inhibiting DNA polymerase. Cell apoptosis by cytarabine was induced dose dependently, which may play a role in cell cycle regulation and show that induces quiescent and proliferating tumor cells (12). DNA microarray technology has been used to gain an understanding of biochemical pathway function, and identify gene functions and medicine targets (13). To gain insight into MDS exposure to Ara-C, we investigated the use of gene chip and RNA sequencing (RNA-seq) on SPARC overexpression combined with Ara-C. The results of the DNA microarray were used to determine transcription factor analysis (Tfscan), to detected the mechanism of transcription factors contact long non-coding RNA (IncRNA) regulate genes and promotes programmed cell death. 


\section{Materials and methods}

Construction of SPARC recombinant lentivirus. We used a lentivirus vector containing a CMV-driven GFP reporter and a U6 promoter upstream of the cloning sites (AgeI and EcoRI) to clone SPARC mRNA. The target sequence for SPARC was, 5'-CCAGGTGGAAGTAGGAGAATT-3'; and the NC-GFP-LV sequence was, 5'-TTCTCCGAACGTGTCACGT-3'. SPARC cDNA was amplified by reverse transcription-polymerase chain reaction (RT-PCR) and subcloned into a lentiviral vector pGC-GV SPARC (Jikai, Shanghai, China). This allowed for the construction of a recombinant lentiviral vector designated as pGC-GV-SPARC. According to the operation manual, the packaging of the retrovirus in 293 cells, Lipofectamine 2000, pHelper 1.0 and pHelper 2.0 (Jikai) were used, prior to the collection of the supernatants for determination.

Cell culture. The MDS/AML cell line SKM-1 was provided by Professor Zhou Jianfeng at Tongji Medical College, Huazhong University of Science Technology and cultured in a RPMI-1640 medium prior to its supplementation with $10 \%$ fetal bovine serum (Gibco-BRL, Grand Island, NY, USA) in a humid atmosphere at $37^{\circ} \mathrm{C}$ with $5 \% \mathrm{CO}_{2}$.

Cells transfection using SPARC recombinant lentivirus. The cells were cultured in 6 -well plates $\left(10^{6}\right.$ cells $\left./ \mathrm{ml}\right)$ and infected with lentivirus at a multiplicity of infection (MOI) of 100 for $10 \mathrm{~h}$. The medium was then replaced with a more basic medium. After 4 days, the cells were observed under a fluorescence microscope and flow cytometry to evaluate the efficiency of the infection.

RT-PCR and quantitative PCR. The total RNA of the samples in each group was extracted from the cells using RNAiso Plus (Takara Biotechnology, Dalian, China) and was then used for cDNA synthesis. In terms of the RT-PCR, each well ( $25 \mu \mathrm{l}$ reaction volume) contained 12.5 $\mu \mathrm{l}$ Taq (Takara Biotechnology), $1 \mu \mathrm{l}$ of each primer $(10 \mu \mathrm{mol} / \mathrm{l}), 2 \mu \mathrm{lDNA}$ template $(50 \mathrm{ng} / \mu \mathrm{l})$

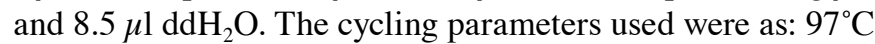
for $5 \mathrm{~min}$, then 30 cycles of $97^{\circ} \mathrm{C}$ for $1 \mathrm{~min}, 56^{\circ} \mathrm{C}$ for $30 \mathrm{sec}$ and $72^{\circ} \mathrm{C}$ for $30 \mathrm{sec}$, and a final extension at $72^{\circ} \mathrm{C}$ for $7 \mathrm{~min}$. The RT-PCR results were analyzed using the Quantity One software (Bio-Rad, Co., Hercules, CA, USA).

Quantitative PCR was performed using an ABIPRISM 7500 Real-Time PCR system (Applied Biosystems, Co., Hercules, CA, USA). The total reaction system was $25 \mu \mathrm{l}$ : SYBR Premix Ex Taq II (12.5 $\mu \mathrm{l}), 1 \mu \mathrm{l}$ of each primer $(10 \mu \mathrm{mol} / \mathrm{l})$ and $2 \mu \mathrm{l}$ cDNA template $(50 \mathrm{ng} / \mu \mathrm{l})$, and $\mathrm{ddH}_{2} \mathrm{O}(8.5 \mu \mathrm{l})$. All the primers were designed using Primer 5 software and synthesized by Takara Biotechnology (Table I). The relative gene expression levels were quantified using the equation $2^{-\Delta \Delta \mathrm{Ct}}$.

Western blot analysis. The cells were lysed in $100 \mu 1$ of a RIPA buffer supplemented with $1 \mu \mathrm{l}$ of PMSF, and the protein concentration of the lysate was determined using a BCA protein assay kit (Beyotime, Beijing, China). A total of $50 \mu \mathrm{g}$ of protein per lane was separated by SDS-PAGE and transferred to the PVDF membranes. The membranes were blocked with $5 \%$ skim milk for $2 \mathrm{~h}$ and incubated overnight at $4^{\circ} \mathrm{C}$ with primer antibodies (mouse anti-human monoclonal antibody
Table I. Quantitative PCR primers used in the present study.

\begin{tabular}{|c|c|c|}
\hline Genes & Forward and reverse primers & $\begin{array}{l}\text { Product } \\
\text { length }(\mathrm{bp})\end{array}$ \\
\hline SPARC & $\begin{array}{l}\text { F: 5'-GGCCTGGATCTTTCTCCTT-3 } \\
\text { R:5'-CCCACAGATACCTCACCTC-3' }\end{array}$ & 126 \\
\hline$\beta$-actin & $\begin{array}{l}\text { F: 5'-CCACGAAACTACCTTCAACTAA-3' } \\
\text { R:5'-GTGATCTCCTTCTGCATCCTGT-3' }\end{array}$ & $3^{\prime} \quad 132$ \\
\hline CD164L2 & $\begin{array}{l}\text { F: 5'-CACCCTCACCTCCAAGGAC-3' } \\
\text { R 5'-GTGACC'TGAGTTCCCAGA-3' }\end{array}$ & 106 \\
\hline MLKL & $\begin{array}{l}\text { F: 5'-TGTCTTTTCTCTCGTAGTT-3' } \\
\text { R:5'-GAAGTCTGTGTTTTCCTCA-3' }\end{array}$ & 184 \\
\hline GALR3 & $\begin{array}{l}\text { F: 5'-CCCCTCGCAAGCAGCCTCTGGG-3' } \\
\text { R:5'-TGCAGGGCGTGCTTGAGGGG-3' }\end{array}$ & 3' 118 \\
\hline ELP5 & $\begin{array}{l}\text { F: 5'-ATCTGGACCCTCCTACCTCTGG-3' } \\
\text { R 5'-GATGCAGGCCTTCCAAGTTCT-3' }\end{array}$ & ' 157 \\
\hline NT5C2 & $\begin{array}{l}\text { F: 5'-TGTTCTGAAAGCTGGGAGCA-3' } \\
\text { R:5'-AGAAACTGACCTGAGTTTAA-3' }\end{array}$ & 136 \\
\hline AFM & $\begin{array}{l}\text { F: 5'-TTCATTTTTATTTTTTATAG-3' } \\
\text { R:5'-AAGTTGCCAGAAGGAACC-3' }\end{array}$ & 141 \\
\hline ATM & $\begin{array}{l}\text { F: 5'-AATACGGAAATGTTAAGAAA-3' } \\
\text { R:5'-GAATGTGCCTCTAATTGTAC-3' }\end{array}$ & 142 \\
\hline AKT1 & $\begin{array}{l}\text { F: 5'-CCCGTTTTCAGACACAGCTC-3' } \\
\text { R:5'-CTGCCTTCCCGTTGACCCAG-3' }\end{array}$ & 137 \\
\hline AKT3 & $\begin{array}{l}\text { F: 5'-GTTCCTGTGTTAGTTTGCTT-3' } \\
\text { R:5'-CTGCAAAGGACATGATCTTG-3' }\end{array}$ & 105 \\
\hline TP73 & $\begin{array}{l}\text { F: 5'-CCTACGCACA ACCCAGCTCC-3' } \\
\text { R:5'-TCCCCTCCAACACCGACTAC-3' }\end{array}$ & 117 \\
\hline RFWD2 & $\begin{array}{l}\text { F: 5'-CAATATTTCTACCAAATCAG-3' } \\
\text { R: 5'-AGAAACACGTACTCCACCAA-3' }\end{array}$ & 112 \\
\hline
\end{tabular}

SPARC, secreted protein acidic and rich in cysteine; MLKL, mixed lineage kinase domain-like; GALR3, galanin receptor 3; ELP5, elongator acetyltransferase complex subunit 5; NT5C2, 5'-nucleotidase cytosolic II; AFM, afamin.

1:1,000; Abcam, Burlingame, CA, USA) for SPARC/ATM/ AKT3/AKT1/RFWD2/TP73. This was followed by incubation using HRP-conjugated goat anti-rabbit or HRP-conjugated goat anti-mouse $(1: 1,000)$ for $1 \mathrm{~h}$ at $37^{\circ} \mathrm{C}$. The membranes were washed four times with TBST and developed using the ECL method. The band intensity was analyzed with Quantity One software.

Annexin $V$ and 7-AAD assay of apoptosis. The cells were collected $\left(10^{6}\right.$ cells $\left./ \mathrm{ml}\right)$ and washed twice with phosphatebuffered saline (PBS) before suspension in $200 \mu \mathrm{l}$ binding buffer, $1 \mu \mathrm{l}$ Annexin V-PE and $5 \mu 1$ 7-AAD (KeyGen Biotech, Shanghai, China) in the dark for $15 \mathrm{~min}$. The infection efficiency and the apoptotic cells were determined by flow cytometry with CellQuest software (BD Biosciences, USA). The pre-experimental testing time period for detecting apoptosis was $48 \mathrm{~h}$. 

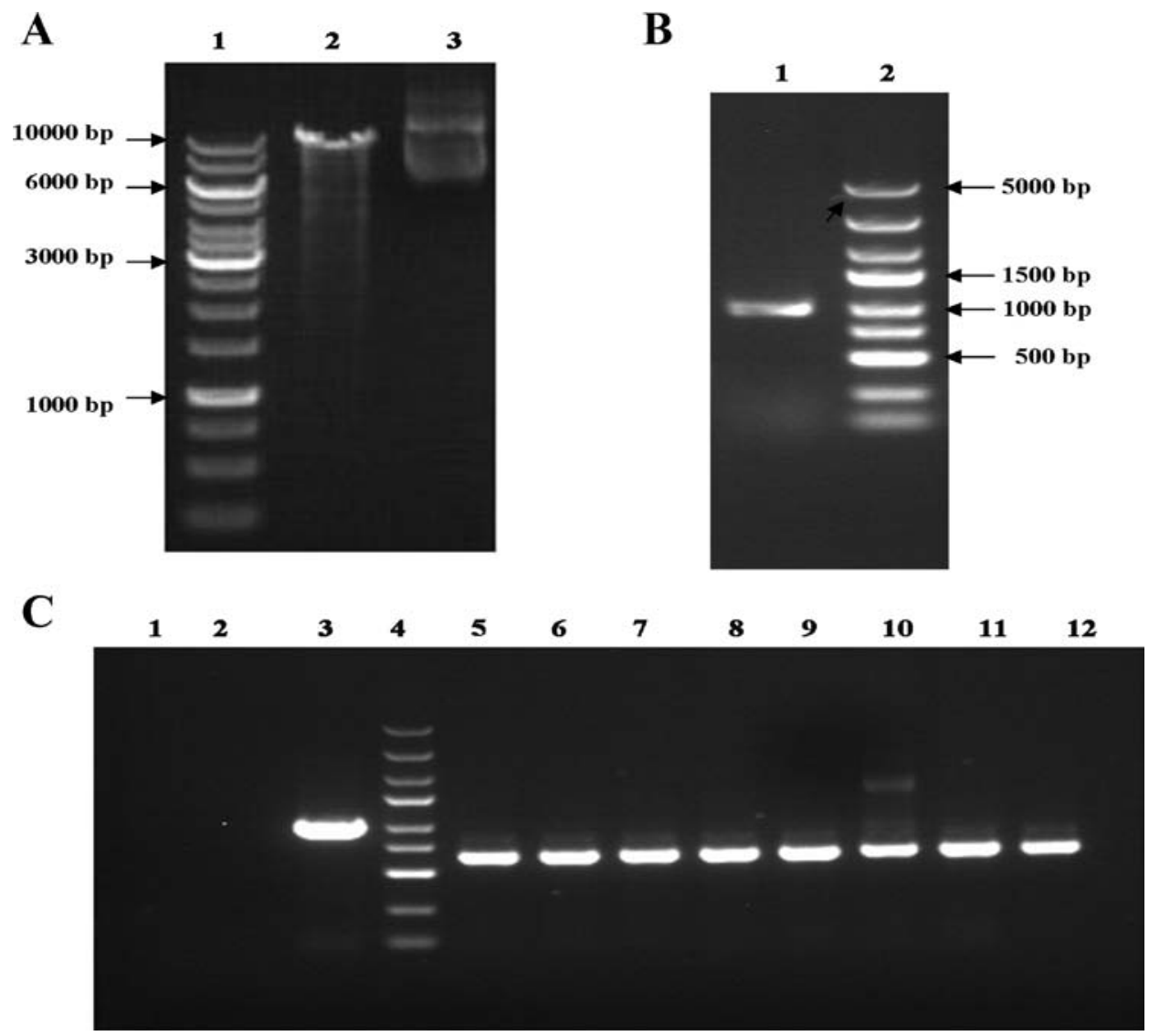

Figure 1. Enzyme products and identification of pGC-GV-SPARC. (A) pGC-GV-EGFP was analyzed using SDS-PAGE. (Lane 1, marker; lane 2, enzyme products; lane 3, non-enzyme products). (B) SPARC fragment electrophoresis results by PCR (lane 1, SPARC; lane 2, marker). (C) PCR identifies pGC-GVSPARC recombinant [lane 1, the negative control $\left(\mathrm{ddH}_{2} \mathrm{O}\right)$; lane 2, NC-GFP-LV; lane 3, positive control]; lane 4, marker (from top to bottom: 3,2, 1.5 and $1 \mathrm{~kb}$; and 750, 500, 250 and $100 \mathrm{bp}$, respectively); lanes 5-12, SPARC transformant. SPARC, secreted protein acidic and rich in cysteine.

Affymetrix experiments and microarray data analysis. Total RNA was extracted from the cells using TRIzol (Takara Biotechnology). This process was completed according to the manufacturer's instructions. The RNA samples examined were derived from SKM-1 cells, SKM-1 cells treated with Ara-C, and pGC-GV-SPARC-infected cells treated with Ara-C. For each sample, $50 \mathrm{ng}$ of the total RNA were amplified and labeled with the two-cycle 'cDNA Synthesis' and the 'Two-Cycle Target Labeling and Control Reagent' packages (Affymetrix, Santa Clara, CA, USA), according to the manufacturer's instructions. The cell intensity calculation and scaling were then performed, using GeneChip operating software (GCOS). Data analysis was performed using GeneSpring 7.3 (Agilent Technologies, USA) and clustering analysis.

TFscan images. The sequences of the differential expression genes were identified using Jemboss software (Sanger Institute, Hinxton, Cambridge). To determine the relationship between genes and transcription factors, the correlation between the gene and transcription factor sequences were identified. A transcription factor regulation network (TF-Gene-Network) was established regarding the interaction between the genes and transcription factors. The networks core transcription factor was identified as the most important center with the largest degree (14). The Pearson correlation analysis was used to measure the regulatory ability of the transcription factors by calculating the correlation between the transcription factors and genes they regulate, as well as the correlation between genes regulated by the same factors.

Statistical analysis. The results were presented as the mean \pm SE and were analyzed by Graphpad Prism 5 software. Each experiment was repeated three times to ensure replication. The groups were compared through analysis by one-way ANOVA. $\mathrm{P}<0.05$ was considered to indicate a statistically significant result.

\section{Results}

Sequencing result of antisense DNA fragment is in accordance with the known SPARC gene. An enzyme digested the lentiviral pGC-GV-EGFP vector, and the products in $2 \%$ agarose gel electrophoresis. As shown in Fig. 1A, the enzyme digestion products released in the second lane were $9,983 \mathrm{~kb}$. The results are consistent with the hypothesis that these products could be used during the subsequent connection reaction. After using the pcDNA-SPARC amplification of the SPARC gene as primers of PCR templates (Fig. 1B), we obtained the $955 \mathrm{bp}$ target fragment, indicating the successful extraction of SPARC.

Vector construction and verification of the positive clone using PCR. The pGC-GV-SPARC lentiviral vector-positive clone PCR fragment size was $627 \mathrm{bp}$, a size consistent with the enzyme results. The SPARC sequence obtained from 

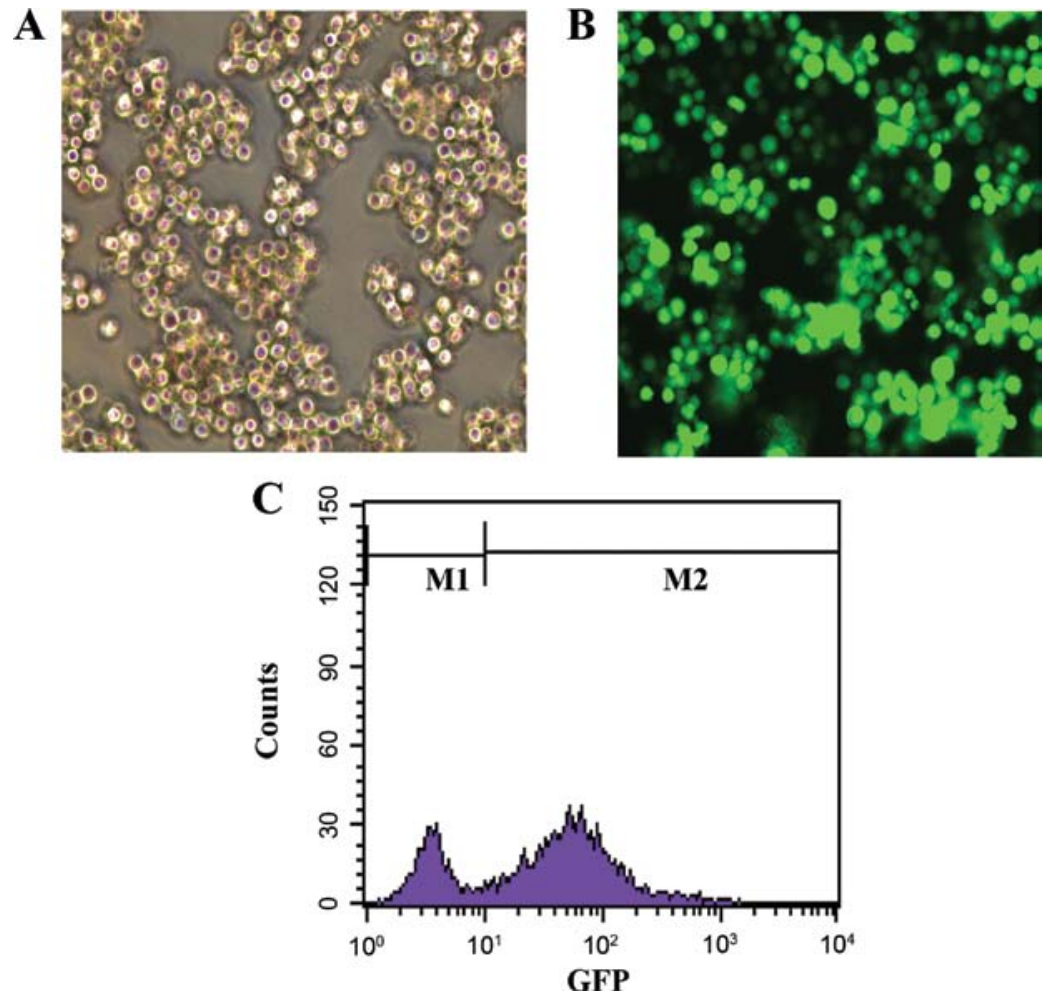

Figure 2. Infection of SKM-1 cells by SPARC-expressing vector (pGC-GV-SPARC) results in stable transduction and ectopic expression of SPARC. (A) Normal SKM-1 cells; (B) SKM-1 cells infected by pGC-GV-SPARC; (C) transduction efficiency detected by flow cytometry. M1, no EGFP; M2, EGFP. Transduction efficiency was $72 \%$. SPARC, secreted protein acidic and rich in cysteine.

A

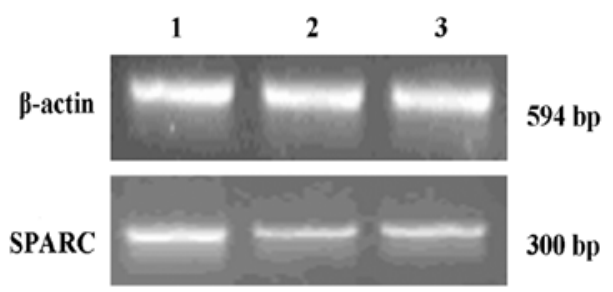

B

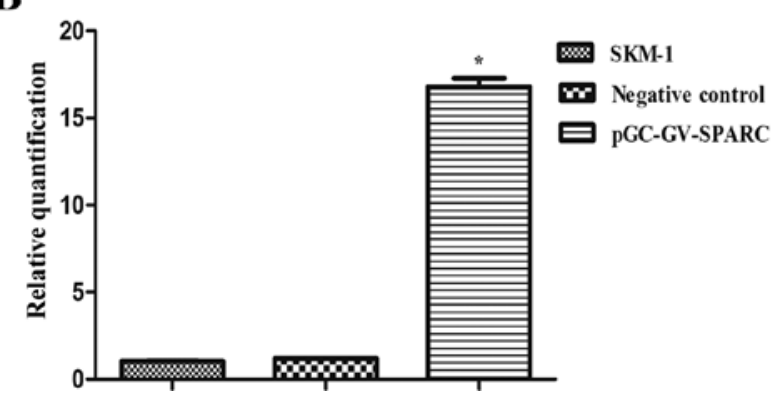

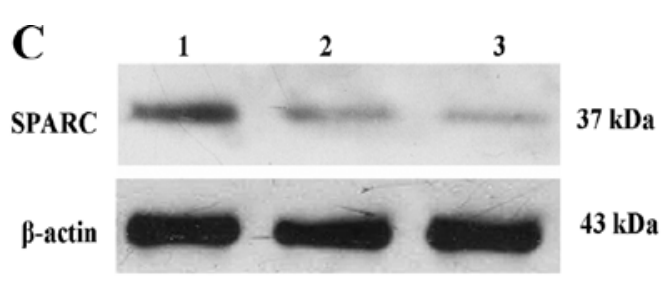

D

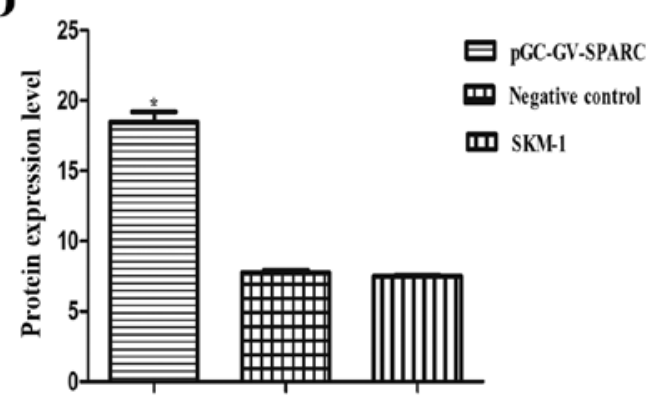

Figure 3. Normal SPARC expression and overexpression in SKM-1 cells. (A) RT-PCR shows the expression of SPARC mRNA.Lane 1, pGC-GV-SPARC-infected SKM-1 cells; lane 2, SKM-1 cells infected with empty vector control; lane 3, normal SKM-cells. (B) RT-PCR data showing the relative expression of SPARC mRNA in SKM-1 cells in different conditions. " $\mathrm{P}<0.05$. (C) Protein was measured by western blot analysis showing the expression of SPARC protein. Lane 1 , pGC-GV-SPARC-infected SKM-1 cells; lane 2, SKM-1 cells infected with empty vector control; lane 3, normal SKM-1 cells. (D) Protein expression levels in the different groups. SPARC, secreted protein acidic and rich in cysteine.

pGC-GV SPARC was the same as that of GenBank (Fig. 1C). This result confirmed that we obtained the correct expression product.

SPARC overexpression by lentivirus mediated in SKM-1 cells. We constructed the SPARC overexpression lentivirus vector and infected the SKM-1 cells. After the infection, we found that $67.88 \pm 1.26 \%$ of cells were GFP-positive, indicating high infection efficiency (Fig. 2). After 5 days, the $2^{-\Delta \Delta \mathrm{Ct}}$ value of cells treated with the SPARC overexpression was increased to 13.2-15.7 when compared to the $2^{-\Delta \Delta C t}$ values of the other two groups. RT-PCR and western blot analysis showed that the SPARC overexpression significantly increased SPARC levels for mRNA and protein (Fig. 3). 
A

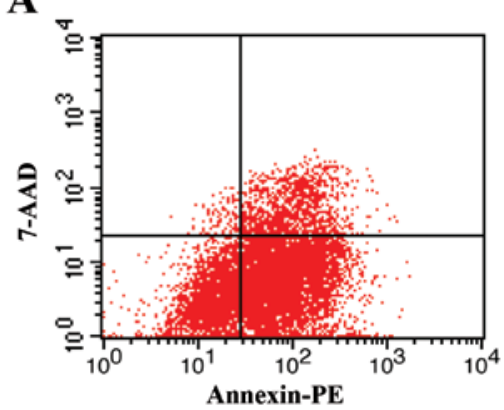

C

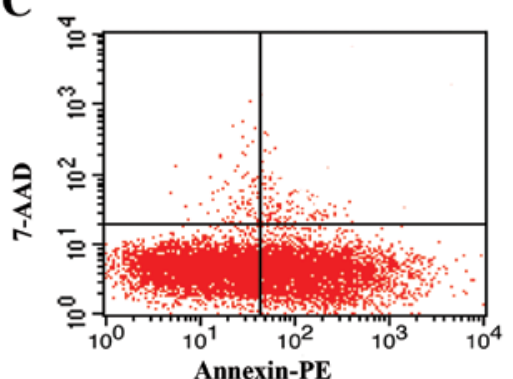

$\mathbf{E}$

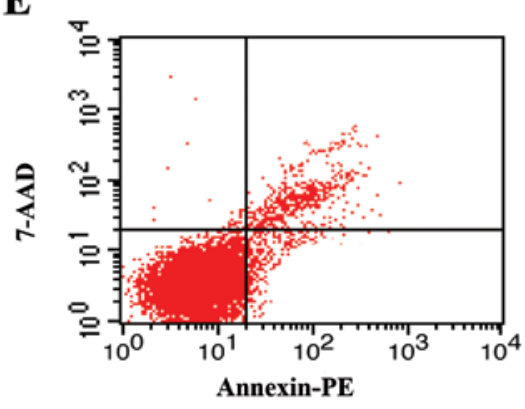

B

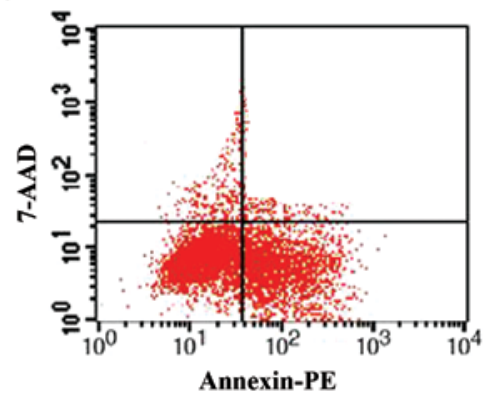

D

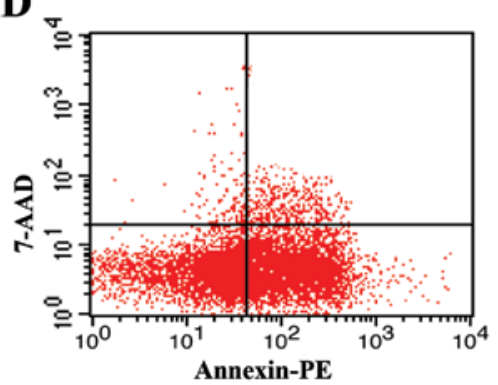

F

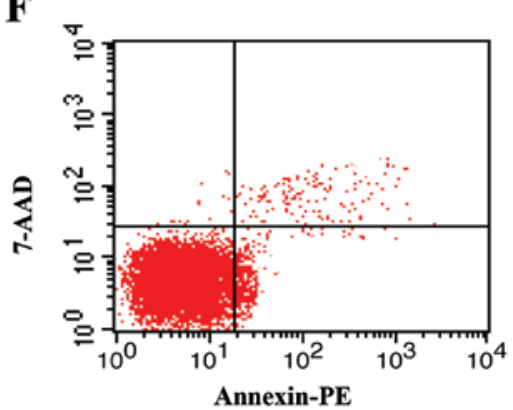

G

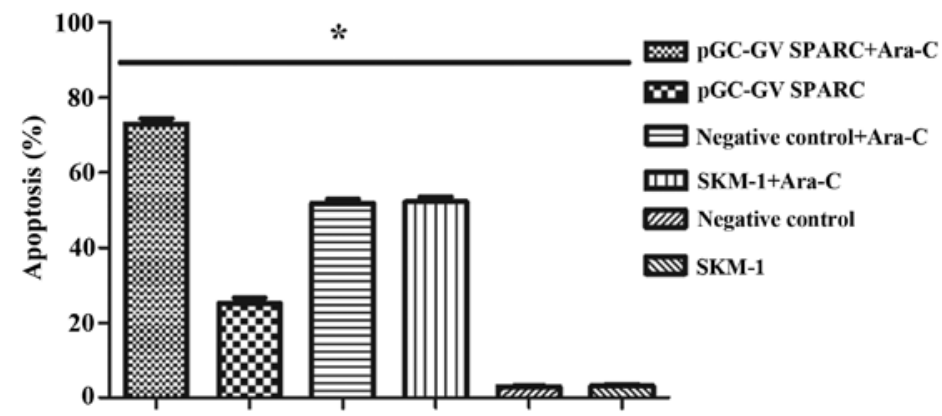

Figure 4. Apoptotic effects on SKM-1 cells after SPARC overexpression and Ara-C treatment. SKM-1 cells were used for all the assays. (A) pGC-GVSPARC-infected and Ara-C treated; (B) pGC-GV-SPARC-infected cells; (C) empty vector negative control infection and Ara-C treatment; (D) normal SKM-1 cells treated with Ara-C; (E) empty vector negative control infection; (F) normal SKM-1 cells; and (G) apoptosis results show *P<0.01 vs. other groups. Data were analyzed by Graph Pad Prism-5 software. SPARC, secreted protein acidic and rich in cysteine; Ara-C, analogue cytosine arabinoside.

Flow cytometric analysis SPARC overexpression associated with Ara-C in MDS cell apoptosis. To elucidate the mechanism by which SPARC with Ara-C inhibits the proliferation of MDS cells, we performed a flow cytometric analysis to evaluate apoptosis. The data showed $\sim 70 \%$ cell apoptosis with SPARC overexpression and Ara-C. In this instance, the growth inhibition percentage of cells was much higher than that of the other groups $(\mathrm{P}<0.05)$ (Fig. 4). These data indicate that the SPARC overexpression associated with Ara-C inhibited MDS cell proliferation, corresponding to the MTS results.
Gene transcription responses to Ara-C exposure. Our experiment is based on a comparison of two groups: SKM-1 cells treated with Ara-C and SPARC-overexpressing SKM-1 cells treated with Ara-C. The analysis of the microarray results revealed an upregulated expression in 566 genes and a downregulated expression in 106 gene transcription levels (Fig. 5). The genes with the high up- and downregulations identified were: mixed lineage kinase domain-like ( $M L K L)$, CD164 silomucin-like-2 protein (CD164L2) and galanin receptor 3 (GalR3), and 5'-nucleotidase cytosolic II (NT5C2), elongator 


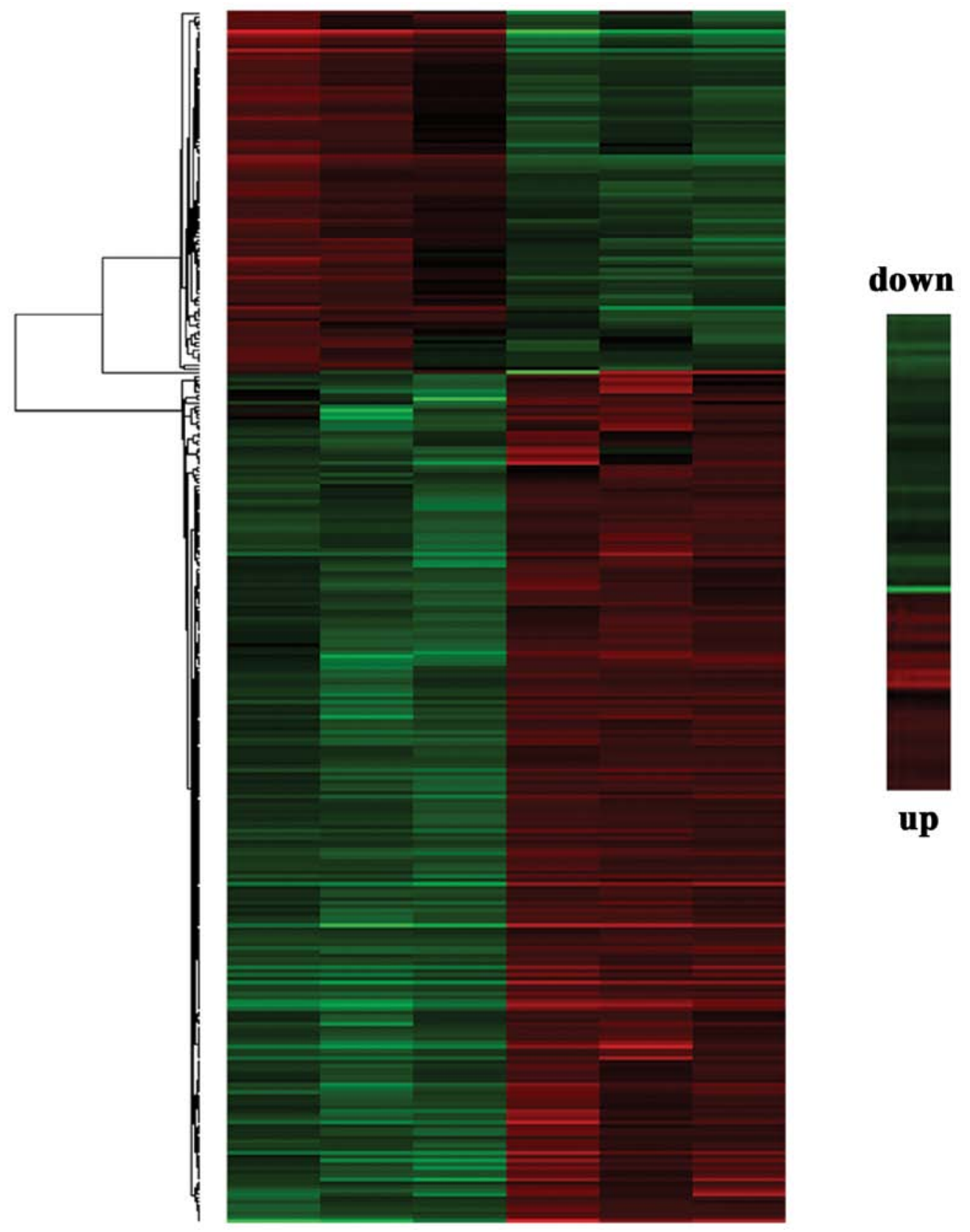

Figure 5. Hierarchical clustering of 672 differentially expressed genes in the SKM-1 cells treated with Ara-C and SPARC-overexpressing SKM-1 cells treated with Ara-C. Each row represents a single Affymetrix probe set. SPARC, secreted protein acidic and rich in cysteine; Ara-C, analogue cytosine arabinoside.

acetyltransferase complex subunit 5 (ELP5), and afamin $(A F M)$. These genes were selected for further investigation according to their relevance to cell death and disease. The mRNA expression levels of these genes were tested by a qPCR to validate our microarray results. As shown in Fig. 6A and B, the RT-PCR results matched our expression study, as was the case for the microarray experiment results for the 6 genes.

Transcription factors regulating the 69 genes and IncRNA. We predicted lncRNA ranged from upstream $10 \mathrm{~kb}$ to downstream $10 \mathrm{~kb}$ for MLKL, CD164L2, GalR3, NT5C2, ELP5, $A F M$ and the target gene SPARC. A transcription factor analysis on lncRNA and the seven genes was performed. The TF-lncRNA-gene-net demonstrated that the 69 genes and IncRNA were controlled by transcription factors, mainly-CPBP and ZNF333 (Fig. 7). ZNF333 is a member of the subfamily of the zinc finger gene complex, localized on chromosome 19p13.1 (15). The cDNA encoded a predicted protein of 290 amino acids. It also created a designated core promoter-binding protein (CPBP) with three zinc fingers (type Cys2-His2) at the end of its C-terminal domain, a serine/threonine-rich central region, and an acidic domain lying within the $\mathrm{N}$-terminal region. In the cotransfection assays, CPBP increased the transcription from a minimal promoter containing its natural DNA-binding site (16).

Changes in apoptosis-associated genes in the microarray results. In our RNA sequencing study, five apoptosis pathway genes were associated with the seven genes and transcription 

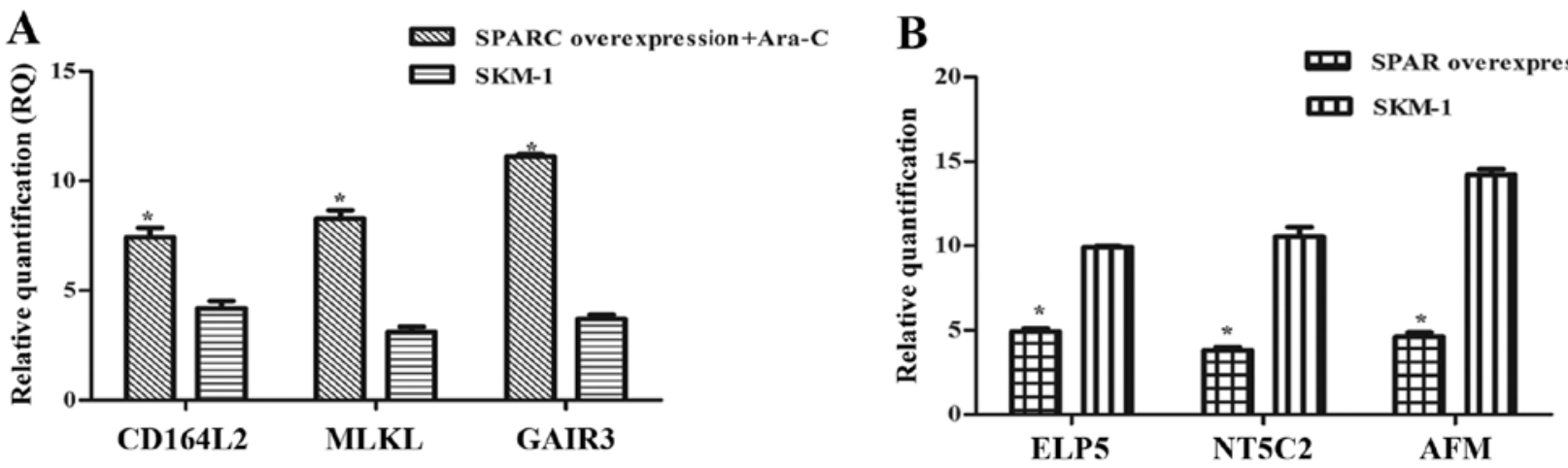

Figure 6. Validating microarray data by qPCR. (A) CD164L2, MLKL and GalR3 were increased when SPARC overexpression associated with Ara-C, the $2^{-\triangle \Delta C t}$ value increased to 6.81-14.37 vs. other groups. (B) ELP5, NT5C2 and AFM expression was decreased to a value of 3.67-13.55. MLKL, mixed lineage kinase domain-like; GALR3, galanin receptor 3; SPARC, secreted protein acidic and rich in cysteine; Ara-C, analogue cytosine arabinoside; ELP5, elongator acetyltransferase complex subunit 5; NT5C2, 5'-nucleotidase cytosolic II; AFM, afamin.

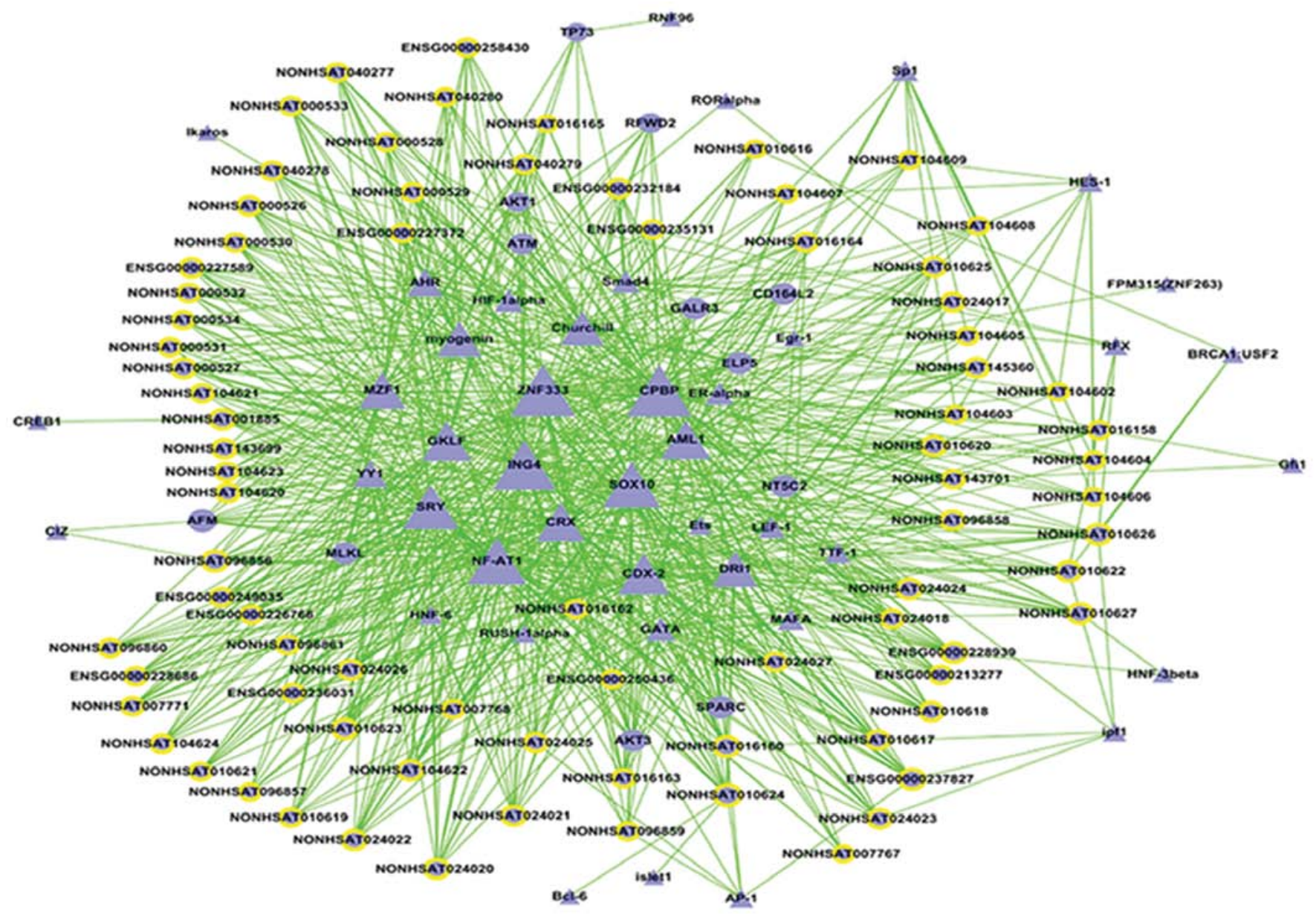

Figure 7. Transcription factor analysis. Triangle, transcription factor; circle, selected gene from microarray results; amd yellow circle, lncRNA. ZNF333 and CPBP are the main transcription factors. IncRNA, long non-coding RNA; CPBP, core promoter-binding protein.

factors. The ATM, AKT3, AKT1, RFWD2 and TP73 possess anti-apoptotic effects, which occurs as a TF-mRNA relationship. Fig. 8 manifests this cyber-relation improvement, showing the relationships between the different genes and transcription factors. For the PCR, western blot analysis confirmed that the expression of ATM, AKT3, AKT1, RFWD2 and TP73 was increased (Figs. 9 and 10).

\section{Discussion}

The role of SPARC in hematology and other malignancies is complex and dependent on the basis of the cell type and malignant tumor $(17,18)$. The present study aimed to investigate the function of SPARC overexpression and associate it with Ara- $C$ in the context of MDS. We selected a human MDS cell 


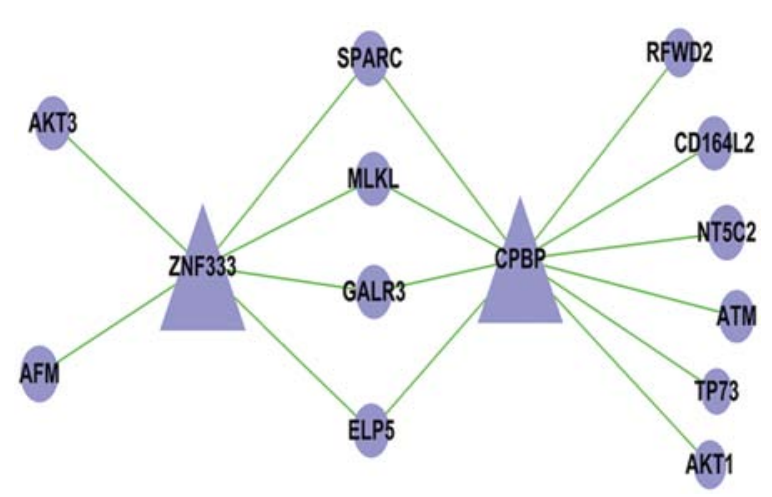

Figure 8. Coexpressed gene modules regulated by specific transcription factors. TF-IncRNA-gene-net shows the transcription factor interaction with the genes. Triangle, transcription factor; circle, selected genes from microarray results. SPARC, secreted protein acidic and rich in cysteine; MLKL, mixed lineage kinase domain-like; CPBP, core promoter-binding protein; NT5C2, 5'-nucleotidase cytosolic II; GalR3, galanin receptor 3; AFM, afamin; ELP5, elongator acetyltransferase complex subunit 5 .

line, SKM-1, with a complex abnormal karyotype including $\operatorname{del}(9 q), i(17 q)$ and $t(17 p)(19)$. SKM-1 was a cell line derived from a male patient with acute myeloid leukemia as a result of MDS (20). When pGC-GV-SPARC was transfected into SKM-1, over $60 \%$ of GFP-positive cells showed that the vector system was successfully constructed.
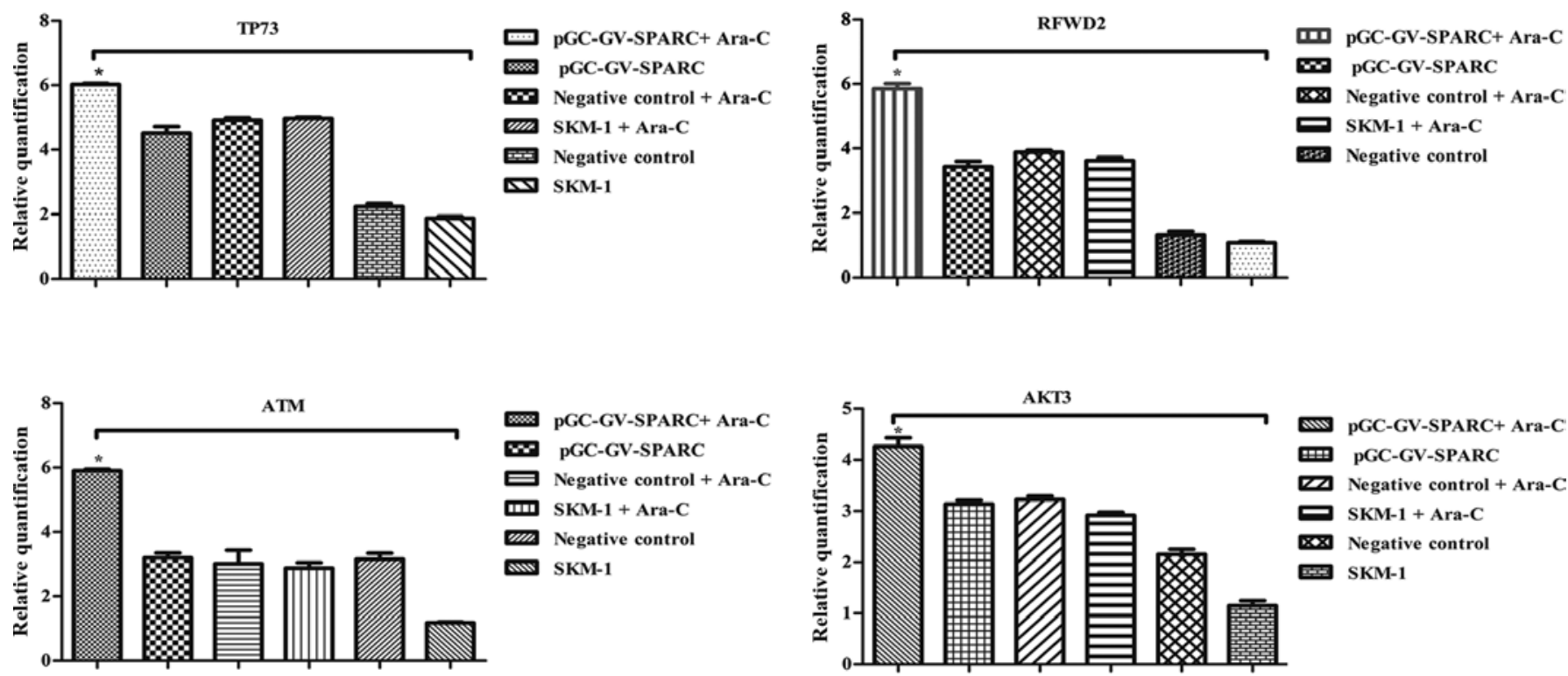

Upregulation of the SPARC mRNA levels was verified by qPCR against the normal SKM-1 SPARC mRNA levels and those of the infected cells with an empty negative control vector. Overexpression of SPARC was detected and confirmed by western blot analysis. Increased SPARC protein content in the cells was repeatedly associated with a recorded inhibition of the SKM-1 cells transduced by the pGC-GV-SPARC vector, in comparison to normal SKM-1 cells and SKM-1 cells infected with an empty vector. Further assessment by flow cytometry demonstrated a significant increase in the number of pro-apoptotic and dead cells of the transduced cell line. These numbers reached $30 \%$ of the cells tested, paralleling the observed antiproliferation effect that the overexpression of SPARC exerted on the cells.

Since SPARC overexpression induces quiescent and inhibits the proliferation of MDS cells, we assessed the effects of cell treatment using Ara-C, a common MDS treatment. We combined this with chemotherapeutic drugs. The results of the present study show that, the apoptotic effect of SPARC overexpression associated with Ara-C was obvious when compared to the upregulation of SPARC in the cells alone. Cell apoptosis was approximately $20-30 \%$. Our flow cytometric analysis showed that the apoptosis of SPARC-overexpressing cells following the treatment with Ara-C increased 50\% in the nontreated controls and 30\% in the normal SKM-1 cells. These conditions suggest a synergy of the mechanisms that lead to

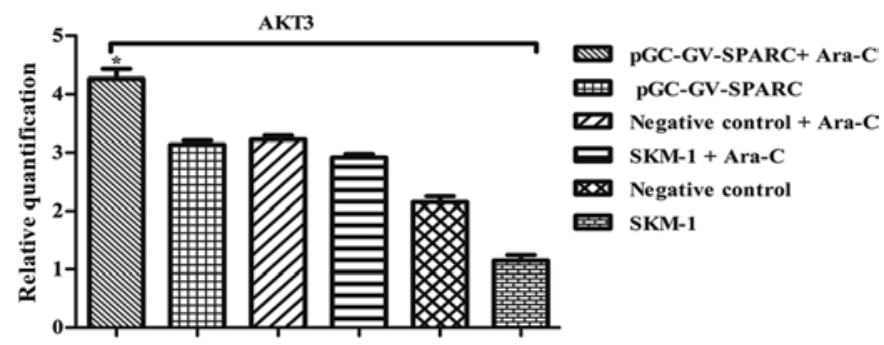

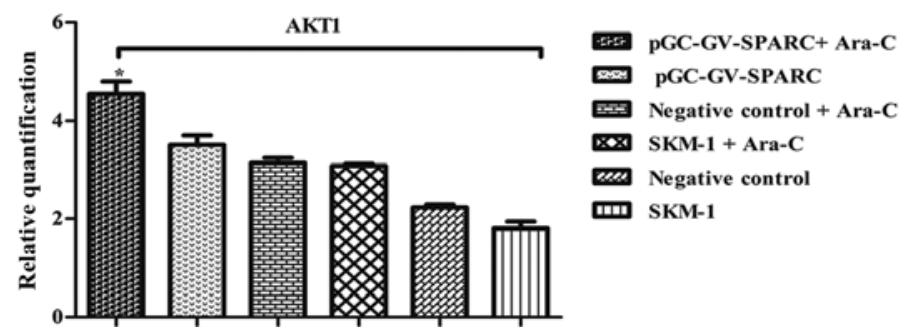

Figure 9. The cell growth-related genes from the microarray results by RT-PCR. ATM, AKT3, AKT1, RFWD2 and TP73 were increased when SPARC overexpression was associated with Ara-C, the $2^{-\Delta \Delta \mathrm{Ct}}$ value increased to 5.42-6.35 vs. other groups. SPARC, secreted protein acidic and rich in cysteine; Ara-C, analogue cytosine arabinoside. 

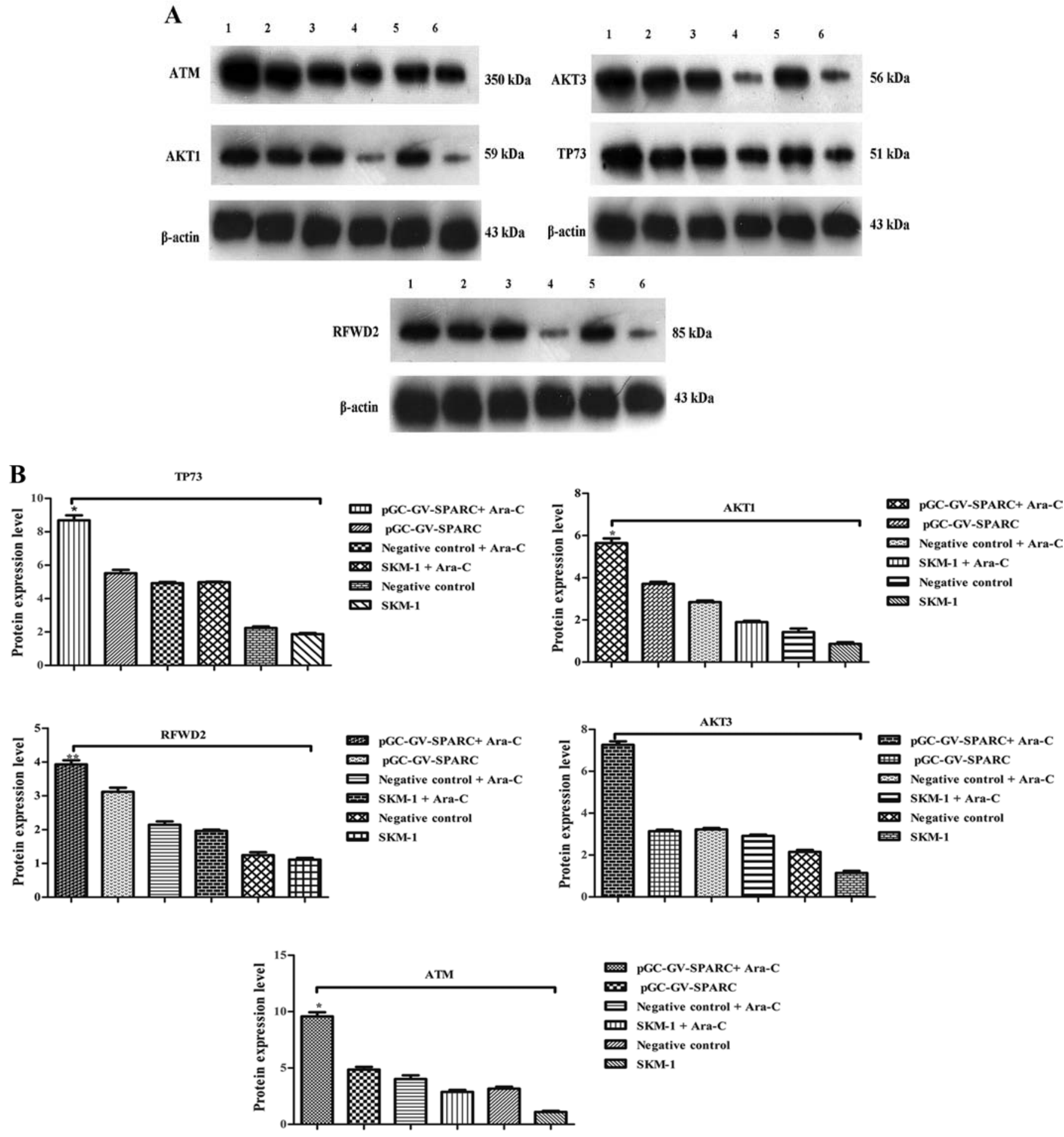

Figure 10. Regulation of gene cell apoptosis from the microarray results by western blotting. (A) Lane 1, pGC-GV-SPARC + Ara-C-treated; lane 2, pGC-GVSPARC; lane 3, negative control + Ara-C; lane 4, SKM-1 cells + Ara-C; lane 5, negative control; lane 6, normal SKM-1 cells. Protein expression for ATM, AKT3, AKT1, RFWD2 and TP73 was increased after SPARC overexpression was associated with Ara-C. (B) Quantitative analysis of western blotting results by Quantity One software, ${ }^{*} \mathrm{P}<0.05,{ }^{* *} \mathrm{P}<0.01$. SPARC, secreted protein acidic and rich in cysteine; Ara-C, analogue cytosine arabinoside.

cell death, or possibly a sensitization effect of one of the two conditions. By contrast, our results from this and a previous study, exhibit proliferation inhibition and increased cell death after SPARC overexpression or silencing in the MDS SKM-1 cell line (21). These contradicting results of SPARC involvement in the biology of different cell types, underscores the pleiotropic function and effects of SPARC protein in the cell life cycle and its complex role in disease where its involvement is unique sometimes promoting growth and survival, whereas it also leads to the inhibition of proliferation and apoptosis.

Gene chip technology was employed to determine the mechanism involved in the association between gene changes and Ara-C. It is notable that for the six genes, we identified the CD164L2, MLKL and GalR3 genes as being extensively 
upregulated in the SPARC-overexpressed cells when treated with Ara-C. CD164L2 has been found to be associated with essential hypertension in a recent study (22). However, it has been reported that cell apoptosis was increased following the co-administration of SPARC overexpression and the Ara-C drug. MLKL regulates necrotic plasma membrane permeabilization, and promotes necrotic cell death (23). Stimulation of GalR3 promotes the survival of adult neural stem cells in response to diabetic milieu (24). Nevertheless, ELP5, NT5C2 and AFM were downregulated. ELP5 was initially identified as a component of a hyper-phosphorylated RNA polymerase II (RNAPII) holoenzyme isolated from budding yeast chromatin and subsequently from the human melanoma cells (25). It has been reported that NT5C 2 mutations predict the possibility of a relapse of acute lymphoblastic leukemia (26). In the present study, we have found that NT5C2 is decreased when Ara-C is present in MDS cells. In addition, AFM is a novel human vitamin E-binding glycoprotein characterization, and we investigated its in vitro expression in the present study (27). To the best of our knowledge, vitamin $\mathrm{E}$ is an antioxidant that delays aging (28). We suggest that AFM alters the effect of vitamin $\mathrm{E}$, thus, that cell apoptosis is increased, enhancing pharmacokinetics.

Transcription factors are essential for the regulation of gene expression and are consequently found in all living organisms. The number of transcription factors increase with genome size, and larger genomes tend to have more transcription factors per gene (29). A new class of transcripts, known as lncRNAs, has been recently found to be pervasively transcribed in the genome. These mRNA-like molecules, which lack significant protein-coding capacity and previously considered a part of dark matter, now have been used in a wide range of biological functions (30). By combining microarray data analysis, Tfscan demonstrated the ZNF333 and CPBP regulation of the gene and lncRNA transcription. These significant transcription factors are key regulatory elements that control gene expression. They act on the mRNA expression of ATM, AKT3, AKT1, RFWD2 and TP73 to allow the CD164L2, MLKL, GalR3, ELP5, NT5C2 and AFM and the SPARC genes to change collectively. ATM mainly modulates apoptosis via the regulation of p53/TP53-dependent anti-apoptotic genes (31). It induces resistance of the chemotherapy drug cisplatin in glioma cells when underexpressed (32). Studies have shown the sensitization of Ara-C may is associated with ATM. AKT1 leads to the activation of AKT3, and both play a role in cell survival. E3 ubiquitin-protein ligase mediates ubiquitination and subsequent proteasomal degradation of target proteins function in RFWD2 (33). This directly involves p53 (TP53) ubiquitination and degradation, thereby abolishing p53-dependent transcription and apoptosis. The P53 signaling pathway includes TP73, serine/threonine protein kinase, which activates checkpoint signaling following double-strand breaks (DSBs), as well as apoptosis and genotoxic stresses such as ionizing ultraviolet A light (UVA) (34). This process allows it to act as a DNA damage sensor. These genes therefore are associated with cell growth and death. Transcription factors regulate the expression of these genes, which may be useful in identifying the SKM-1 apoptosis mechanism.

The expression of SPARC is correlative with P53 in MDS. The haploinsufficiency of SPARC induces the change of P53 in the 5q-syndrome (35). P53 is a well-known tumor suppressor that impedes the cell cycle at the G1-S checkpoint (34). Our microarray results determined that ATM, RFWD2 and TP73 are subject to the P53 signaling pathway, particularly ATM, which acts directly on P53. According to these analyses, we assumed that when the gene was regulated, tumor cell apoptosis mediated P53.

Controlling gene expression associated with chemotherapy drugs has been used in different diseases, and some progress has been made in ERG when combined with chemotherapy for leukemia (36). Similar findings were identified for atherosclerosis (37). The present results show that, SPARC regulates SKM-1 cell proliferation and apoptosis, which is associated with Ara-C. In conclusion, SPARC overexpression inhibits cell proliferation, induces cell apoptosis and activates the pathway gene change. The results as presented suggest that SPARC may have anti-oncogene properties for MDS and acts as a tumor suppressor in 5q-syndrome. Reference source not found. These findings are important in pathogenetics and in the treatment of MDS. SPARC combined medication may be a useful method in curing hematonosis.

\section{Acknowledgements}

The present study was supported by the National Natural Science Foundation of China (nos. 30971277, 81250034 and 30370618), the Natural Science Foundation of Chongqing (CSTC, 2009BB5070), the Science and Technology Commission of the Chongqing (no. 0135414105), the Health Bureau of Chongqing (2013-2-023) and the Project Foundation of Chongqing Municipal Education Committee (2013, 2014).

\section{References}

1. Ghariani I, Braham N, Hassine M and Kortas M: Myelodysplastic syndrome classification. Ann Biol Clin 71: 139-144, 2013 (In French)

2. Jädersten M and Hellström-Lindberg E: New clues to the molecular pathogenesis of myelodysplastic syndromes. Exp Cell Res 316: 1390-1396, 2010.

3. Visconte V, Selleri C, Maciejewski JP and Tiu RV: Molecular pathogenesis of myelodysplastic syndromes. Transl Med UniSa 8: 19-30, 2014.

4. DiMartino JF, Lacayo NJ, Varadi M, Li L, Saraiya C, Ravindranath Y, Yu R, Sikic BI, Raimondi SC and Dahl GV: Low or absent SPARC expression in acute myeloid leukemia with MLL rearrangements is associated with sensitivity to growth inhibition by exogenous SPARC protein. Leukemia 20: 426-432, 2006.

5. Rotllant J, Liu D, Yan YL, Postlethwait JH, Westerfield M and Du SJ: Sparc (Osteonectin) functions in morphogenesis of the pharyngeal skeleton and inner ear. Matrix Biol 27: 561-572, 2008.

6. Hsiao YH, Lien HC, Hwa HL, Kuo WH, Chang KJ and Hsieh FJ: SPARC (osteonectin) in breast tumors of different histologic types and its role in the outcome of invasive ductal carcinoma. Breast J 16: 305-308, 2010.

7. Wiese AH, Auer J, Lassmann S, Nährig J, Rosenberg R, Höfler H, Rüger $\mathrm{R}$ and Werner M: Identification of gene signatures for invasive colorectal tumor cells. Cancer Detect Prev 31: 282-295, 2007.

8. Said N, Frierson HF Jr, Chernauskas D, Conaway M, Motamed K and Theodorescu D: The role of SPARC in the TRAMP model of prostate carcinogenesis and progression. Oncogene 28: 3487-3498, 2009.

9. Isler SG, Ludwig CU, Chiquet-Ehrismann R and Schenk S: Evidence for transcriptional repression of SPARC-like 1, a gene downregulated in human lung tumors. Int J Oncol 25: 1073-1079, 2004. 
10. Boultwood J, Pellagatti A, Cattan H, Lawrie CH, Giagounidis A, Malcovati L, Della Porta MG, Jädersten M, Killick S, Fidler C, et al: Gene expression profiling of $\mathrm{CD} 34^{+}$cells in patients with the 5q-syndrome. Br J Haematol 139: 578-589, 2007.

11. Duong VH, Komrokji RS and List AF: Efficacy and safety of lenalidomide in patients with myelodysplastic syndrome with chromosome 5q deletion. Ther Adv Hematol 3: 105-116, 2012.

12. Koren-Michowitz M, Maayan H, Apel A, Shem-Tov N, Yerushalmi R, Volchek Y, Avigdor A, Shimoni A and Nagler A: Salvage therapy with ARA-C and gemtuzumab ozogamicin in AML patients relapsing after stem cell transplantation. Ann Hematol 94: 375-378, 2015.

13. Strauss C, Endimiani A and Perreten V: A novel universal DNA labeling and amplification system for rapid microarray-based detection of 117 antibiotic resistance genes in Gram-positive bacteria. J Microbiol Methods 108: 25-30, 2015.

14. Prieto C, Risueño A, Fontanillo $C$ and De las Rivas J: Human gene coexpression landscape: Confident network derived from tissue transcriptomic profiles. PLoS One 3: e3911, 2008.

15. Jing Z, Liu Y, Dong M, Hu S and Huang S: Identification of the DNA binding element of the human ZNF333 protein. J Biochem Mol Biol 37: 663-670, 2004.

16. Slavin D, Sapin V, López-Diaz F, Jacquemin P, Koritschoner N, Dastugue B, Davidson I, Chatton B and Bocco JL: The Krüppellike core promoter binding protein gene is primarily expressed in placenta during mouse development. Biol Reprod 61: 1586-1591, 1999.

17. Alachkar H, Santhanam R, Maharry K, Metzeler KH, Huang X, Kohlschmidt J, Mendler JH, Benito JM, Hickey C, Neviani P, et al: SPARC promotes leukemic cell growth and predicts acute myeloid leukemia outcome. J Clin Invest 124: 1512-1524, 2014.

18. Pellagatti A, Jädersten M, Forsblom AM, Cattan H, Christensson B, Emanuelsson EK, Merup M, Nilsson L, Samuelsson J, Sander B, et al: Lenalidomide inhibits the malignant clone and up-regulates the SPARC gene mapping to the commonly deleted region in 5q-syndrome patients. Proc Natl Acad Sci USA 104: 11406-11411, 2007.

19. Kimura S, Kuramoto K, Homan J, Naruoka H, Ego T, Nogawa M, Sugahara S and Naito H: Antiproliferative and antitumor effects of azacitidine against the human myelodysplastic syndrome cell line SKM-1. Anticancer Res 32: 795-798, 2012.

20. Nakagawa T and Matozaki S: The SKM-1 leukemic cell line established from a patient with progression to myelomonocytic leukemia in myelodysplastic syndrome (MDS)-contribution to better understanding of MDS. Leuk Lymphoma 17: 335-339, 1995.

21. Nian Q, Xiao Q, Wang L, Luo J, Chen LP, Yang ZS and Liu L: SPARC silencing inhibits the growth of acute myeloid leukemia transformed from myelodysplastic syndrome via induction of cell cycle arrest and apoptosis. Int J Mol Med 33: 856-862, 2014

22. Lu J, Li M, Zhang R, Hu C, Wang C, Jiang F, Yu W, Qin W, Tang S and Jia W: A common genetic variant of FCN3/CD164L2 is associated with essential hypertension in a Chinese population. Clin Exp Hypertens 34: 377-382, 2012.

23. Dondelinger Y, Declercq W, Montessuit S, Roelandt R, Goncalves A, Bruggeman I, Hulpiau P, Weber K, Sehon CA, Marquis RW, et al: MLKL compromises plasma membrane integrity by binding to phosphatidylinositol phosphates. Cell Rep 7: 971-981, 2014
24. Mansouri S, Barde S, Ortsäter H, Eweida M, Darsalia V, Langel U, Sjöholm A, Hökfelt T and Patrone C: GalR3 activation promotes adult neural stem cell survival in response to a diabetic milieu. J Neurochem 127: 209-220, 2013.

25. Close P, Gillard M, Ladang A, Jiang Z, Papuga J, Hawkes N, Nguyen L, Chapelle JP, Bouillenne F, Svejstrup J, et al: DERP6 (ELP5) and C3ORF75 (ELP6) regulate tumorigenicity and migration of melanoma cells as subunits of Elongator. J Biol Chem 287: 32535-32545, 2012

26. Meyer JA, Wang J, Hogan LE, Yang JJ, Dandekar S, Patel JP, Tang Z, Zumbo P, Li S, Zavadil J, et al: Relapse-specific mutations in NT5C2 in childhood acute lymphoblastic leukemia. Nat Genet 45: 290-294, 2013.

27. Hubalek M, Buchner H, Mörtl MG, Schlembach D, Huppertz B, Firulovic B, Köhler W, Hafner E, Dieplinger B, Wildt L, et al: The vitamin E-binding protein afamin increases in maternal serum during pregnancy. Clin Chim Acta 434: 41-47, 2014.

28. Johnson EJ: Age-related macular degeneration and antioxidant vitamins: Recent findings. Curr Opin Clin Nutr Metab Care 13: 28-33, 2010.

29. Gill G: Regulation of the initiation of eukaryotic transcription. Essays Biochem 37: 33-43, 2001.

30. Quek XC, Thomson DW, Maag JL, Bartonicek N, Signal B, Clark MB, Gloss BS and Dinger ME: IncRNAdb v2.0: Expanding the reference database for functional long noncoding RNAs. Nucleic Acids Res 43 (Database issue): D168-D173, 2015.

31. Zou Y, Wang Q, Li B, Xie B and Wang W: Temozolomide induces autophagy via ATM-AMPK-ULK1 pathways in glioma. Mol Med Rep 10: 411-416, 2014.

32. Cowley AW Jr, Moreno C, Jacob HJ, Peterson CB, Stingo FC, Ahn KW, Liu P, Vannucci M, Laud PW, Reddy P, et al: Characterization of biological pathways associated with a $1.37 \mathrm{Mbp}$ genomic region protective of hypertension in Dahl S rats. Physiol Genomics 46: 398-410, 2014.

33. Cubillos-Rojas M, Amair-Pinedo F, Peiró-Jordán R, Bartrons R, Ventura F and Rosa JL: The E3 ubiquitin protein ligase HERC2 modulates the activity of tumor protein $\mathrm{p} 53$ by regulating its oligomerization. J Biol Chem 289: 14782-14795, 2014.

34. Liebermann DA, Hoffman B and Vesely D: p53 induced growth arrest versus apoptosis and its modulation by survival cytokines. Cell Cycle 6: 166-170, 2007.

35. Boultwood J, Pellagatti A and Wainscoat JS: Haploinsufficiency of ribosomal proteins and p53 activation in anemia: DiamondBlackfan anemia and the 5q-syndrome. Adv Biol Regul 52: 196-203, 2012

36. Goldberg L, Tijssen MR, Birger Y, Hannah RL, Kinston SJ, Schütte J, Beck D, Knezevic K, Schiby G, Jacob-Hirsch J, et al: Genome-scale expression and transcription factor binding profiles reveal therapeutic targets in transgenic ERG myeloid leukemia. Blood 122: 2694-2703, 2013.

37. Linden F, Domschke G, Erbel C, Akhavanpoor M, Katus HA and Gleissner CA: Inflammatory therapeutic targets in coronary atherosclerosis-from molecular biology to clinical application. Front Physiol 5: 455, 2014. 